\title{
Narrative review of the management of stage IIIA non-small cell lung cancer: does different management equal different quality of life?
}

\author{
Jason Trevis $^{1+\wedge}$, Patrick Barclay ${ }^{2 \#}$, Nicholas Marshall ${ }^{3}$, Cecilia Pompili ${ }^{4}$ \\ ${ }^{1}$ Department of Cardiothoracic Surgery, James Cook University Hospital, Middlesbrough, UK; ${ }^{2}$ Hull Royal Infirmary, Hull, UK; ${ }^{3}$ Royal Victoria \\ Infirmary, Newcastle-upon-Tyne, UK; ${ }^{4}$ Department of Cardiothoracic Surgery, St James University Hospital/University of Leeds, Leeds, UK \\ Contributions: (I) Conception and design: J Trevis, C Pompili; (II) Administrative support: J Trevis; (III) Provision of study materials or patients: All \\ authors; (IV) Collection and assembly of data: All authors; (V) Data analysis and interpretation: All authors; (VI) Manuscript writing: All authors; (VII) \\ Final approval of manuscript: All authors. \\ "These authors contributed equally to this work. \\ Correspondence to: Jason Trevis. Department of Cardiothoracic Surgery, James Cook University Hospital, Marton Road, Middlesbrough, TS4 3BW, \\ UK. Email: Jason.trevis@doctors.org.uk.
}

\begin{abstract}
Lung cancer remains the leading cause of cancer related deaths worldwide. A state of equipoise exists due to the expansive evidence base and increasing number of randomised trials testing promising therapeutic drugs and combined treatments. Treatment success should be determined through measuring both efficacy and the maintenance of quality of life (QoL). QoL in lung cancer patients is reported as being lower than in other malignancies, with independence and the ability to perform normal activities ranking as the most important issues. Management of stage IIIA non-small cell lung cancer (NSCLC) remains contentious due to its heterogeneity. For resectable disease, QoL and survival remain higher in those receiving lung parenchyma sparing surgery, such as lobectomy/bilobectomy, compared with pneumonectomy. The addition of neoadjuvant or adjuvant chemotherapy further improves outcomes and has become the standard of care. Whilst some research on QoL in patients receiving chemotherapy has consistently reported a negative correlation between the number of treatment cycles and QoL, other studies have found that chemotherapy may show positive effects on specific QoL domains such as functional activity and pain. Comparatively chemoradiotherapy (CRT) is more effective at reducing tumour/nodal size in resectable disease with no subjective decrease in QoL with the addition of radiotherapy (RT) (despite its increased toxicity) highlighting its potential use as an adjunct. In non-resectable stage IIIA NSCLC, definitive CRT remains the mainstay of treatment. Its efficacy has been well established when compared with RT or supportive care alone. Patients report improved QoL when receiving CRT compared with chemotherapy. Assessing possible effects on health-related QoL remains important when planning multi-modality cancer therapy. This review discusses the differing/compounding impact different treatment strategies for stage IIIA NSCLC have upon patient's QoL and reported outcomes.
\end{abstract}

Keywords: Lung cancer; non-small cell lung cancer (NSCLC); stage IIIA; quality of life (QoL)

Received: 05 June 2020; Accepted: 27 November 2020; Published: 25 May 2022.

doi: $10.21037 /$ ccts-20-114

View this article at: http://dx.doi.org/10.21037/ccts-20-114

\footnotetext{
$\wedge$ ORCID: 0000-0002-3450-3066.
} 


\section{Introduction}

\section{Background—stage IILA lung cancer}

Lung cancer remains the leading cause of cancer related deaths worldwide (1), with over 1.8 million new cases each year of which $80-85 \%$ are non-small cell lung cancer (NSCLC) $(1,2)$. At the time of diagnosis, around 50\% of cases are locally advanced, defined as stage III by the $8^{\text {th }}$ Edition of the Lung Cancer Stage Classification (3). Further subclassification provides distinction between nodal status with important implications upon the decision-making process for management, prognosis and overall long-term outcomes. Regarding treatment options, stage IIIA NSCLC may be differentiated into resectable or unresectable disease, thus requiring accurate pre-operative staging. Following subclassification, the therapeutic options remain broad, including; neoadjuvant chemotherapy or chemoradiotherapy (CRT) followed by surgery, surgery followed by adjuvant chemotherapy with or without adjuvant radiotherapy (RT), or definitive CRT without surgery (4), and more recently, the addition of targeted therapies (e.g., immunotherapy).

\section{Objectives}

Aiming to briefly discuss the management options for stage N2/IIIA NSCLC, whilst primarily addressing their differing/compounding impact upon patient's quality of life (QoL) and reported outcomes. We present the following article in accordance with the Narrative Review reporting checklist (available at https://ccts.amegroups.com/article/ view/10.21037/ccts-20-114/rc).

\section{Methods}

The following search strategy was employed in order to identify high quality systematic reviews, meta-analyses and relevant studies to fully explore the objectives established for this narrative review; Medline search (1966-June 2020) using the Ovid interface. Key words: Lung cancer, non-small cell lung cancer, NSCLC, stage IIIA, management, treatment, chemotherapy, radiotherapy, surgery, chemoradiotherapy, outcome, QoL, patient reported outcomes (PROs). This was supplemented with hand searches of literature from personal experience in writing numerous studies/reviews in this field of research.

\section{Discussion}

\section{What the guidelines recommend}

The heterogeneity of stage IIIA N2 disease is reflected in the treatment combinations available. A lack of a universally agreed definition on resectability and descriptors of lymph node $(\mathrm{LN})$ characteristics, coupled with unclear randomised evidence, means contention remains on what the optimal treatment is (5). Treatment approaches from the National Institute for Health and Care Excellence (NICE), American College of Chest Physicians (ACCP), and European Society for Medical Oncology (ESMO) highlight this heterogeneity with consensus maintained on a multimodal approach (Table 1).

There remains an emphasis on the utilisation of the multidisciplinary team, patient preference, high volume centres, and for individual patient risks to be taken into account (6-8). Generally, there is acceptance for the use of surgery in low volume (non-bulky) mediastinal node involvement (6-8). NICE however specifically recommends the use of trimodality treatment for all resectable N2 disease. Therapies based on definitive CRT remain reserved for more extensive, higher volume (bulky) and unresectable disease (6-8). With regards to immunotherapy, due to its relative infancy, guidance is yet to reflect its routine use stating that there is currently no place for targeted therapy in the treatment of stage IIIA N2 NSCLC; other than within clinical trials $(7,8)$.

\section{QoL and lung cancer}

QoL in lung cancer patients is reported to be lower than in those suffering from other malignancies (9). Research has shown that routine collection of QoL data effectively supplements clinical evaluation and laboratory results, whilst helping to predict survival (9) particularly in lung cancer patients. Assessment through patient reporting allows for the potential to uncover needs that would not otherwise be found by the physician, as demonstrated by significant incongruity between clinicians' ratings and patients self-reporting $(10,11)$. QoL data can also help to guide therapeutic decision making (9); of particular importance when a pathology confers little outcome for return to full health or is deemed incurable. The aim therefore becomes to improve health related QoL, defined by Ebrahim as being 'determined by QoL and modified by physical impairment, limitation of functional state, 
Table 1 Overview of treatment strategies recommended by the UK, European and American guidelines [modified from Putora et al. (5)]

\begin{tabular}{lll}
\hline Guideline & Resectable & Non resectable \\
\hline NICE & LN extent: single station (LN non-bulky and bulky = definitive surgery + neo/adjuvant chemotherapy/CRT) & Definitive CRT \\
& LN extent: multi-station single zone (LN non-bulky and bulky = definitive surgery + neo/adjuvant \\
& chemotherapy/CRT) \\
& LN extent: multizone (LN non-bulky and bulky = definitive surgery + neo/adjuvant chemotherapy/CRT) \\
ESMO & LN extent: single station (LN bulky and non-bulky = NP) \\
& LN extent: multi-station single zone (Bulky and non-bulky = definitive CRT) \\
& LN extent: multizone (Bulky and non-bulky = definitive CRT) \\
ACCP & LN extent: single station (Bulky = definitive CRT; non-bulky = NP) \\
& LN extent: multi-station single zone (Bulky = definitive CRT; non-bulky = NP) \\
& LN extent: multizone (Bulky = definitive CRT; non-bulky = NP)
\end{tabular}

LN, Iymph node; CRT, chemoradiotherapy; NP, no preference on any modality; NICE, National Institute for Health and Care Excellence; ACCP, American College of Chest Physicians; ESMO, European Society for Medical Oncology.

perceptions, and opportunities of social activity' (12).

Together, disease severity and progression impact negatively upon QoL in lung cancer patients. QoL is further compounded by symptom severity and number, treatment side effects, type of cancer, tumour localisation, and prognosis for cure and survival (9). The mental and social resources of a patient before the onset of disease are also crucial (9). Research suggests that patients assess their functioning in five dimensions: physical, psychological, cognitive, social, and life roles. Both generalised and disease-specific symptoms have been shown to exacerbate psychological symptoms (13). Functional impairment is said to be the most important risk factor for depression (13), together with independent contribution from fatigue, symptom burden, and performance status (14). Therapeutic success should not only be determined by efficacy and prolongation of survival, but also the achievement of a satisfactory level of self-assessed QoL, where independence and the ability to perform normal activities rank as the most important issues among lung cancer patients (15).

\section{Resectable stage IILA NSCLC}

Surgery continues to be a mainstay management option for patients in early stage disease (I and II), where the mean five-year survival rate is $90 \%$ for pathological stage I, declining to $41 \%$ in confirmed stage IIIA disease (3). There continues to be controversy around the efficacy of surgery for this group of patients, especially so for N2 disease (16).
In comparison to earlier stage disease, stage IIIA NSCLC patients have more postoperative complications, such as longer median hospital stay and higher proportions of arrhythmias (17). Surgery in stage IIIA NSCLC has seen an upward trend in the use of tissue sparing lobectomy in place of the more extensive pneumonectomy (18), which conveys worse survival rates as reported by Schulte et al. of 45 months vs. 31 months respectively (19,20). Albain et al. has reported a similar trend, where higher mortality rates (26\%) with pneumonectomy were observed, reflecting an increased rate of surgical related deaths (8\% compared to $2 \%$ with chemotherapy alone) $(21,22)$. Shao et al. has shown in their albeit small sample size of 51 stage IIIA patients, that those whom underwent video-assisted thoracic surgery (VATS) did not encounter any increase in intraoperative complications, with a mean survival time of (44.0 \pm 2.6 months) and a five-year overall survival (OS) of $51.1 \%$, concluding that VATS in stage IIIA patients is a safe and feasible treatment (23). However, survival rates and QoL for stage IIIA patients continue to show a lack of improvement $(24,25)$.

In the first instance, stage IIIA NSCLC patients generally report lower pre-operative QoL baselines compared to early stage disease patients, highlighted by Yilmaz et al. where a mean preoperative walking distance of $346 \mathrm{~m}$ was described compared to $457 \mathrm{~m}$ in the early stage disease group (26). With lower baseline physiological reserves and thus potential hindrance on daily QoL, preservation of QoL through type of resection should 
be central in decision making. Several studies (27-29) have shown patients receiving lobectomy to have higher levels of QoL when compared to pneumonectomy; mean QoL was $>10$ points higher for the lobectomy group with less pain, coughing and dyspnoea at 24 months (19). Patients receiving lobectomy have also been shown to return to their physical baselines between 1-6 months postoperatively $(19,28,29)$.

However, Schulte et al. has shown that both pneumonectomy and lobectomy patients have worse QoL outcomes when compared to other major visceral operations, such as oesophageal resection, at 24 months post-operatively. Increases in pain, dyspnoea and coughing were reported in both groups, with higher coughing reported in the lobectomy group at discharge (19). Subsequently, both groups demonstrate an expected reduction in QoL at discharge which was slow to recover and ultimately failed to return to preoperative levels at 24 months, particularly in the pneumonectomy group (19). Supported by Ferguson et al.'s meta-analysis, concluding that pneumonectomy was associated with a postoperative increase in breathlessness and pain at 12 months, with continued fatigue, anxiety and physical functioning (dyspnoea) being reported five years on in $34 \%$ of patients $(28,30,31)$. Overall surgery remains a key aspect of treatment for those with resectable stage IIIA NSCLC, however when performed alone it demonstrates poor outcomes, with $30-70 \%$ of patients experiencing recurrence or death $(1,32,33)$.

\section{Chemotherapy}

The standard of care for resectable locally advanced NSCLC requires a multimodal approach whereby the addition of chemotherapy has added benefit. The literature suggests two approaches to chemotherapy for this patient group, namely, induction or adjuvant regimens (1). The NSCLC Metaanalysis Collaborative Group reports a 5\% absolute increase in five-year survival with the use of adjuvant chemotherapy in patients with locally advanced NSCLC (34), representing an increased OS from $30 \%$ to $35 \%$, improving median survival from 45 to 54 months $(35,36)$. This report also highlighted that there was no significant positive or negative effect of chemotherapy on complete resection rate; nor benefit upon locoregional recurrence, with no excess of early mortality in the preoperative chemotherapy arm as a result of deferred surgery (33).
Despite becoming standard of care for stage IIIA lung cancer management, the routine collection of QoL outcomes for this treatment modality and specific subclassification remain minimal. In advanced stage lung cancer, chemotherapy aims to decrease tumour mass, reduce cancer associated symptoms and therefore improve QoL following cessation of treatment related side effects (37). The desire for symptom relief may even exceed the wish for survival (38). However, the literature addressing the impact of chemotherapy upon QoL in lung cancer patients in general reports a negative correlation between the number of chemotherapy cycles and QoL $(9,37,39)$, particularly in the over 65 age group. Similar trends have been reported by Wintner and colleagues (40), whereby they state that QoL worsens as patients progress through treatment lines, i.e., those receiving third line therapy showed significantly worse QoL compared to those receiving first line therapy. This deterioration was particularly seen in the physical functioning dimension of QoL assessment, thought to be due to the high levels of symptom burden shown by the QLQ-C30 subscales (41). Chemotherapy is also reported to impact upon performance of occupational and family roles in this age group as well as daily duties, including physical and social functioning $(9,37)$. Whilst in the under 65 age group, its impact predominantly limits psychological functioning whereby it is common for levels of anxiety to rise, often related to a reduction in $\mathrm{QoL}(37,42)$.

In contrast, others such as Ranson et al. and Brown have shown that chemotherapy may show positive effects on specific domains e.g. functional activity and pain $(43,44)$. Milosevic and colleagues $(39)$, in a sample of 120 patients ( $25 \%$ stage III), found that chemotherapy was superior to alternative treatment modalities, when compared to symptomatic management only. Reporting an improvement in physical, business, social and emotional functioning, along with a reduction in numerous symptoms, e.g., dyspnoea, insomnia, loss of appetite, dysphagia and haemoptysis. Conversely, they acknowledge the deterioration of other symptoms, i.e., nausea and vomiting, fatigue and hair loss.

Overall, management of disease and treatment related symptoms may improve QoL; with the literature recommending controlling levels of fatigue, pulmonary rehabilitation, social and spiritual support with early instigation of palliative treatment allowing for an improved QoL (9). 


\section{Post-operative radiotherapy}

Up to $40 \%$ of resectable N2 tumours have local recurrence (1) and therefore medical reduction strategies such as RT are required. Nonetheless, the detriment of post-operative radiotherapy (PORT) on OS has been well reported by the PORT Meta-analysis Trialists Group, demonstrating a two-year OS decrease of $7 \%$ in PORT compared to surgery alone (45). Despite this, the detriment of PORT was found to be inversely related to nodal status, with a beneficial trend found for N2 disease (45). The more recent 2016 meta-analysis by Cochrane included this data, expressing an $18 \%$ increase in relative risk of death in the PORT group, reducing OS from $58 \%$ to $53 \%$ (46), stating that the number of patients needed to harm is greater than the number of patients needed to treat (47). However, this meta-analysis reviewed trials from 1966-1998 and as such does not account for current advances in RT technology and techniques.

One trial included in this meta-analysis (48) showed fiveyear OS in those receiving surgery and PORT to be lower (30\%) compared to surgery alone $(43 \%)(\mathrm{P}=0.002)(1,48)$, accountable to a $23 \%$ increase in intercurrent death rate in the PORT group. However, this study showed that this detriment of PORT was in those with stage II disease, with no difference demonstrated in patients with stage I or III (49). This finding is supported by Corso et al. whereby an absolute five-year OS benefit of $6.3 \%$ in the N2 PORT group was found comparable to a detriment of $9.3 \%$ and $4.3 \%$ in the $\mathrm{N} 0$ and $\mathrm{N} 1$ groups respectively (50). When compared with resection as a definitive treatment following induction chemotherapy, research has suggested that PORT has equal efficacy to surgery (51) when measuring median (16.4 vs. 17.5 months) and five-year OS (15.7\% vs. 14\%) (hazard ratio $=1.06,95 \% \mathrm{CI}, 0.84$ to 1.35 ).

Milosevic et al. reported the impact of RT upon QoL showing that patients experienced reduced pain and coughing, with beneficial effects on dyspnoea seen weeks to months post treatment (39). However, this study also highlighted that appetite is decreasing, and nausea and vomiting were worsened by RT (39). When comparing QoL outcomes in patients who underwent either surgery or RT (only) in early stage NSCLC, Schwartz et al. found that there was no significant difference between the two groups scores, with a substantial decline in both physical and mental health QoL seen in both surgical patients and those undergoing RT, concluding that the two modalities are comparable in their effect on QoL (52).

\section{Combined chemoradiotherapy}

The benefit of CRT in decreasing tumour size has been expressed by several studies $(21,53,54)$. Pless et al. demonstrated a pathological complete response/nodal downsizing of $61 \%$ with the addition of neoadjuvant CRT compared with $44 \%$ with neoadjuvant chemotherapy alone (53). When comparing bimodality treatments to trimodality, Sorensen et al. and the meta-analysis by McElnay et al. showed that trimodality treatment (sequential CRT with surgery) improved survival rates when compared to CRT alone $(5,55,56)$. A finding supported by The Intergroup study (INT 0139), where progression free survival (PFS) was $29 \%$ in the neoadjuvant trimodality group $v s .19 \%$ in the bimodal group $(\mathrm{P}=0.02)$ but conversely, $\mathrm{OS}$ was not significantly different at 3 -years (38\% vs. 33\%, respectively) (5). Furthermore, in regard to sequential CRT, Pless et al.'s study (neoadjuvant concurrent CRT with surgery vs. neoadjuvant chemotherapy and surgery) showed that there was no significant difference in event-free survival between trimodality and bimodality treatment $[12.8 v s .11 .6$ months $(\mathrm{P}=0.67)]$ or $\mathrm{OS}$ (37 vs. 26 month) (53). Albain et al. has reported similar findings when comparing neoadjuvant CRT plus surgery $v s$. definitive CRT, finding no overall significant difference in median survival between treatment modalities (23.6 vs. 22.2 months) but did find a 5-year PFS improvement within the trimodality group (median 12.8 months PFS vs. 10.5 months) (21). In turn, this opens the question of whether an increase in aggressive treatment combinations equates to improvements in QoL at the cost of higher toxicity.

Schumacher et al. in their study have shown that there is no subjective decrease in QoL with the addition of concurrent neoadjuvant CRT when compared to sequential in locally advanced NSCLC (57). QoL was assessed before and after each intervention in both groups using the EORTC QLQ-C30 and the QLQ-LC $(41,58)$ where no statistically significant differences between both groups were found (57). Both groups reported lower levels of physical functioning and increases in symptoms of pain, fatigue and dyspnoea at the end of their treatment compared to at the end, finding lower rates of haemoptysis in the CRT group (57). Interestingly, although these reductions in QoL scales were found, there were no significant decreases in "Global health" or "Overall QoL" in either group as one could assume with higher toxicity and decreases in physical function, highlighting the potential use of additional CRT as an adjunct to treatment for stage IIIA NSCLC patients (58). 


\section{Non-resectable stage IIIA NSCLC}

\section{Definitive CRT}

Definitive CRT remains the mainstay of treatment for unresectable stage IIIA NSCLC; due to the local impact of RT, and systemic effect of chemotherapy in the effort to reduce/prevent micrometastases, whilst acting as a radiosensitiser, increasing the therapeutic index of the RT $(1,59)$.

The literature is well established, as reported in the review by Yoon et al., for the survival benefits conferred by CRT when compared to RT or supportive care alone (1). A meta-analysis conducted by Aupérin and colleagues concluded that concurrent CRT granted a 5-year absolute OS benefit of $4.5 \%$ and a decreased locoregional progression by an absolute rate of $6.1 \%$ at 5 years (HR $=0.77)$ when compared to a sequential regimen (60), further solidified by the results from the RTOG 9410 randomised trial (61). Conversely, concurrent CRT has demonstrated significantly increased rates of acute grade 3-4 nonhaematologic toxicity, particularly acute oesophagitis, along with a lack of reduction of distant disease progression compared to sequential $(1,60)$. As a result, there remains a place for sequential CRT, namely in those unable to tolerate concurrent therapy as it has been shown to provide a 5 -year OS advantage over RT alone (1).

When considering QoL outcomes within this group, a randomised trial by Strøm et al. [2013] compared the impact of chemotherapy $v s$. CRT in the palliation of unresectable stage III NSCLC (62). Both survival and QoL were measured and compared between the two arms. QoL was measured using the EORTC QLQ-C30 questionnaire $\mathrm{V} 3$ plus the supplementary questionnaire LC13 (58). Scores ultimately remained static in the CRT arm (though patients reported a significant worsening of their symptoms during treatment). The chemotherapy arm however reported a significant and clinically relevant deterioration in the months following therapy in QoL which unlike the CRT cohort did not return to baseline and progressively worsened. Researchers therefore concluded that CRT (despite the increased toxicity levels) was superior to chemotherapy alone given the higher survival rates and increased reported QoL (62). These results reinforce the findings from an earlier study by Pijls-Johannesma et al. in which QoL was assessed following the use of high-dose RT or concurrent CRT whilst treating lung cancer patients (63). Concluding that QoL decreased after patients received either treatment, thought to be due to treatment-related side effects, but returned to baseline within 3 months (63). Further describing predictors for QoL to be; oesophagitis, gender, tumour stage (whereby stage III disease was associated with increased QoL compared to stage I-II), and fatigue. This study indicates that concurrent CRT or high dose RT is well-tolerated treatment options regarding the preservation of QoL.

\section{Targeted therapy}

Within the population of patients who have received CRT alone, for inoperable advanced NSCLC, there still remains poor outcomes, with most having disease progression and only $15-30 \%$ remaining alive at 5 -years $(64,65)$. As a result, progress has been primarily sought through optimization of CRT regimens. Whilst these regimens demonstrate greater response rates and survival $(1,61,66,67)$, it is burdened with increased toxicity when compared to sequential therapy, generating the need for an efficacious treatment for stage IIIA NSCLC with reduced/minimal related toxicity. The heterogeneity of lung cancer biology has steered investigation into numerous targeted therapies, utilising mutations such as EGFR, ELM4-ALK (1).

\section{Immunotherapy}

It has been suggested that RT may promote tumour immunogenicity (68) through both a synergistic and abscopal effect due to systemic immune activation (67). Promising results have been reported from the PACIFC trial, targeting immune checkpoints through the use of durvalumab in patients with unresectable stage IIIA NSCLC, who have not demonstrated disease progression following concurrent CRT. The trials primary endpoints, OS and PFS have shown significant improvement when compared to placebo, i.e., $66.3 \%$ vs. 55.6\% 24-month OS, 16.8 vs. 5.6 months PFS $(64,65)$. Furthermore, a secondary endpoint analysis published by Hui et al., looked to explore the impact upon PROs. This was of particular importance as the previous standard of care involved observation and can therefore be presumed to have no detriment upon PROs $(64,65)$. It should however be mentioned that a limitation of this study was the possible non-capture of immunotherapy related symptoms from utilising the EORTC questionnaire-originally designed for analysing the impact of chemotherapy (69), thus creating scope 
for further development of such QoL questionnaires for this emerging treatment method. Considering the aforementioned, it was concluded that the addition of up to 12 months of durvalumab did not compromise patients' symptoms, functioning or QoL when compared with placebo (70) supported by a paper by Garassino and colleagues, complementing the clinical safety profile also observed $(64,65,71)$. This is supported by further literature investigating immunotherapies such as nivolumab, pembrolizumab and atezolizumab, which have gained approval for second line treatment of advanced NSCLC, based on a multitude of studies demonstrating increased response rates, OS and PSF over docetaxel (71-79). Whilst also collectively reporting favourable safety outcomes when compared to chemotherapy (platinum based and/ or docetaxel) (71-79). PROs and QoL analysis reported an improved QoL measures at 15 weeks compared to chemotherapy in those receiving pembrolizumab. Overall, these findings suggest that immunotherapies may be an encouraging treatment able to preserve QoL in patients with NSCLC demonstrating improved clinical and QoL measures when compared to the previous optimal treatment of platinum-based chemotherapy (13).

\section{Summary}

Due to the heterogeneity of the lung cancer patients, in presentation, histopathology and response to treatment, treatment success should be viewed from two key standpoints; survival and maintenance of a good QoL (31). The assessment of health-related QoL remains important in the planning of cancer therapy, with success of medical treatment and pulmonary rehabilitation shown to diminish with increasing symptoms, and therefore reducing QoL (26). The basis for improving QoL in lung cancer patients is limited by the number and severity of symptoms, especially fatigue, pain and dyspnoea.

This continues to be a challenging cohort of patients to manage, expressed by the variation in international consensus. Multi-disciplinary management continues to play a crucial role for these patients and QoL considerations need to be discussed with patients during the decision-making process. Therefore, management of these patients should heavily rely on patient centeredness, with treatments offered at an individualised level and implementation of new strategies to predict the evolution of QoL.

\section{Acknowledgments}

Funding: None.

\section{Footnote}

Provenance and Peer Review: This article was commissioned by the Guest Editors (Fabrizio Minervini and Marco Scarci) for the series "Controversies in the Management of Stage IIIA Non-Small-Cell Lung Cancer" published in Current Challenges in Thoracic Surgery. The article has undergone external peer review.

Reporting Checklist: The authors have completed the Narrative Review reporting checklist. Available at https:// ccts.amegroups.com/article/view/10.21037/ccts-20-114/rc

Conflicts of Interest: All authors have completed the ICMJE uniform disclosure form (available at https://ccts. amegroups.com/article/view/10.21037/ccts-20-114/coif). The series "Controversies in the Management of Stage IIIA Non-Small-Cell Lung Cancer" was commissioned by the editorial office without any funding or sponsorship. The authors have no other conflicts of interest to declare.

Ethical Statement: The authors are accountable for all aspects of the work in ensuring that questions related to the accuracy or integrity of any part of the work are appropriately investigated and resolved.

Open Access Statement: This is an Open Access article distributed in accordance with the Creative Commons Attribution-NonCommercial-NoDerivs 4.0 International License (CC BY-NC-ND 4.0), which permits the noncommercial replication and distribution of the article with the strict proviso that no changes or edits are made and the original work is properly cited (including links to both the formal publication through the relevant DOI and the license). See: https://creativecommons.org/ licenses/by-nc-nd/4.0/.

\section{References}

1. Yoon SM, Shaikh T, Hallman M. Therapeutic management options for stage III non-small cell lung cancer. World J Clin Oncol 2017;8:1-20.

2. Jones CM, Brunelli A, Callister ME, et al. Multimodality 
Treatment of Advanced Non-small Cell Lung Cancer: Where are we with the Evidence? Curr Surg Rep 2018;6:5.

3. Detterbeck, FC, Boffa DJ, Kim AW, et al. The Eighth Edition Lung Cancer Stage Classification. Chest 2017;151:193-203.

4. Baik CS, Vallieres E, Martins RG. The role of chemotherapy in the management of stage IIIA nonsmall cell lung cancer. Am Soc Clin Oncol Educ Book 2013;320-5.

5. Putora PM, Leskow $\mathrm{P}, \mathrm{McD}$ onald $\mathrm{F}$, et al. International guidelines on stage III N2 nonsmall cell lung cancer: surgery or radiotherapy? ERJ Open Res 2020;6: 00159-2019.

6. NICE. Lung cancer: diagnosis and management. Available online: https://www.nice.org.uk/guidance/ng122/chapter/ Recommendations\#combination-treatment-for-nonsmall-cell-lung-cancer (accessed 20 May 2020).

7. Ramnath N, Dillinger TJ, Harris LJ, et al. Treatment of Stage III Non-small Cell Lung Cancer;Diagnosis and Management of Lung Cancer, 3rd ed: American College of Chest Physicians Evidence-Based Clinical Practice Guidelines. Chest 2013;143:e314S-e340S.

8. Eberhardt WEE, Ruysscher DD, Weder W, et al. 2nd ESMO Consensus Conference in Lung Cancer: locally advanced stage III non-small-cell lung cancer. Ann Oncol 2015;26:1573-88.

9. Polanski J, Jankowska-Polanska B, Rosinczuk J, et al. Quality of life of patients with lung cancer. Onco Targets Ther 2016:9:1023-8.

10. Pakhomov SV, Jacobsen SJ, Chute CG, et al. Agreement between patient-reported symptoms and their documentation in the medical record. Am J Manag Care 2008;14:530-9.

11. Basch $\mathrm{E}$. The missing voice of patients in drug-safety reporting. N Engl J Med 2010;362:865-9.

12. Ebrahim S. Clinical and public health perspectives and applications of health-related quality of life measurement. Soc Sci Med 1995:41:1383-94.

13. Ramirez RA, Lu J, Thomas KE. Quality of life for non-small cell lung cancer patients in the age of immunotherapy. Transl Lung Cancer Res 2018:7:S149-S152.

14. Hopwood P, Stephens RJ. Depression in patients with lung cancer: prevalence and risk factors derived from qualityof-life data. J Clin Oncol 2000;18:893-903.

15. Gralla RJ, Hollen PJ, Msaouel P, et al. An evidence-based determination of issues affecting quality of life and patient- reported outcomes in lung cancer: results of a survey of 660 patients. J Thorac Oncol 2014;9:1243-8.

16. Van Schil PE, Berzenji L, Yogeswaran SK, et al. Surgical Management of Stage IIIA Non-Small Cell Lung Cancer. Front Oncol 2017;7:249.

17. Lushaj B, Julliard W, Brett T, et al. Resection is safe for patients with stage IIIA NSCLC undergoing multimodality therapy. Cancer Treatment Communications 2016. doi: 10.1016/j.ctrc.2015.12.002.

18. Pöttgen C, Eberhardt W, Stamatis G, et al. Definitive radiochemotherapy versus surgery within multimodality treatment in stage III non-small cell lung cancer (NSCLC) - a cumulative meta-analysis of the randomized evidence. Oncotarget 2017;8:41670-8.

19. Schulte T, Schniewind B, Dohrmann P, et al. The extent of lung parenchyma resection significantly impacts long term quality of life in patients with non-small cell lung cancer. Chest 2009;135:322-9.

20. Aggarwal C, Li L, Borghaei H, et al. Multidisciplinary therapy of stage IIIA non-small-cell lung cancer: longterm outcome of chemoradiation with or without surgery. Cancer Control 2014;21:57-62.

21. Albain KS, Swann R, Rusch V, et al. Radiotherapy plus Ch with or without surgical resection for stage III non-smallcell lung cancer: a phase III randomised controlled trial. Lancet 2009;374:379-86.

22. Haque W, Verma V, Butler EB, et al. Pathologic nodal clearance and complete response following neoadjuvant chemoradiation for clinical N2 non-small cell lung cancer: Predictors and long-term outcomes. Lung Cancer 2019;130:93-100.

23. Shao W, Liu J, Liang W, et al. Safety and feasibility of video-assisted thoracoscopic surgery for stage IIIA lung cancer. Chin J Cancer Res 2014;26:418-22.

24. Lackey A, Donington J. Surgical Management of Lung Cancer. Semin Intervent Radiol 2013;30:133-40.

25. McKenna RJ, Houck W, Fuller CB. Video-assisted thoracic surgery lobectomy: experience with 1,100 cases. Ann Thorac Surg 2006;81:421-5.

26. Yılmaz E, Özalevli S, Ersoz H et al. Comparison of healthrelated quality of life and exercise capacity according to stages in patients with non-small cell lung cancer. Tuberk Toraks 2013;61:131-9.

27. Myrdal G, Valtysdottir S, Lambe M, et al. Quality of life following lung cancer surgery. Thorax 2003;58:194-7.

28. Balduyck B, Hendriks J, Lauwers P, et al. Quality of Life after Lung Cancer Surgery: A Prospective Pilot Study comparing Bronchial Sleeve Lobectomy with 
Pneumonectomy. J Thorac Oncol 2008;3:604-8.

29. Win T, Sharples L, Wells FC, et al. Effect of lung cancer surgery on quality of life. Thorax 2005;60:234-8.

30. Ferguson MK, Karrison T. Does pneumonectomy for lung cancer adversely influence long-term survival? J Thorac Cardiovasc Surg 2000;119:440-8.

31. Yang P. Epidemiology of Lung Cancer Prognosis: Quantity and Quality of Life. Methods Mol Biol 2009;471:469-86.

32. Martini N, Flehinger BJ. The role of surgery in N2 lung cancer. Surg Clin North Am 1987;67:1037-49.

33. Ponn R, Lo Cicero J, Daly BDT. Surgical treatment of non-small cell lung cancer. 6 ed. Philadephia, PA: Lippincott Williams \& Wilkins, 2005:1548-87.

34. NSCLC Meta-analysis Collaborative Group. Preoperative chemotherapy for non-small-cell lung cancer: a systematic review and meta-analysis of individual participant data. Lancet 2014;383:1561-71.

35. Arriagada R, Auperin A, Burdett S, et al. Adjuvant chemotherapy, with or without postoperative radiotherapy, in operable non-small-cell lung cancer: two meta-analyses of individual patient data. Lancet 2010;375:1267-77.

36. Pignon JP, Tribodet H, Scagliotti GV, et al. Lung adjuvant cisplatin evaluation: a pooled analysis by the LACE Collaborative Group. J Clin Oncol 2008;26:3552-9.

37. Karczmarek-Borowska B, Pelc M, Rabiej E, et al. The quality of life of non-small cell lung cancer patients treated with chemotherapy. Pneumonol Alergol Pol 2014;82:349-57.

38. Silvestri G, Pritchard R, Welch HG. Preferences for Ch in patients with advanced non-small cell lung cancer: descriptive study based on scripted interviews. BMJ 1998;317:771-5.

39. Milosevic B, Pejic D, Momcicevic D, et al. Quality of life in lung cancer patients due to treatment. Signa Vitae 2016;11:47-50.

40. Wintner LM, Giesinger JM, Zabernigg A, et al. Quality of life during Ch in lung cancer patients: results across different treatment lines. Br J Cancer 2013;109:2301-8

41. European Organisation for Research and Treatment of Cancer. Quality of Life of Cancer Patients. Available online: https://qol.eortc.org/questionnaire/eortc-qlq-c30/ (accessed 25th May 2020).

42. Li TC, Li CI, Tseng CH, et al. Quality of life predicts survival in patients with non-small cell lung cancer. BMC
Public Health 2012;12:790.

43. Ranson M, Davidson N, Nicolson M, et al. Randomized Trial of Paclitaxel Plus Supportive Care Versus Supportive Care for Patients With Advanced Non-Small-Cell Lung Cancer. J Natl Cancer Inst 2000;92:1074-80.

44. Brown J, Thorpe H, Napp V, et al. Assessment of quality of life in the supportive care setting of the big lung trial in non-small-cell lung cancer. J Clin Oncol 2005;23:7417-27.

45. PORT Meta-analysis Trialists Group. Postoperative radiotherapy in non-small-cell lung cancer: systematic review and meta-analysis of individual patient data from nine randomised controlled trials. Lancet 1998;352:257-63.

46. Burdett S, Rydzewska L, Tierney J, et al. Postoperative radiotherapy for non-small cell lung cancer. Cochrane Database Syst Rev 2016;10:CD002142.

47. Fiorica F. Postoperative radiotherapy and lung cancer in stage III: helpful or harmful. J Thorac Dis 2017;9:E277-8.

48. Dautzenberg B, Arriagada R, Chammard AB, et al. A controlled study of postoperative radiotherapy for patients with completely resected nonsmall cell lung carcinoma. Groupe d'Etude et de Traitement des Cancers Bronchiques. Cancer 1999;86:265-73.

49. Lally BE, Zelterman D, Colasanto JM, et al. Postoperative radiotherapy for stage II or III nonsmall- cell lung cancer using the surveillance, epidemiology, and end results database. J Clin Oncol 2006;24:2998-3006

50. Corso CD, Rutter C, Wilson L, et al. Re-evaluation of the Role of Postoperative Radiotherapy and the Impact of Radiation Dose for Non-Small-Cell Lung Cancer Using the National Cancer Database. J Thorac Oncol 2015;10;148-55.

51. van Meerbeeck JP, Kramer G, Van Schil P, et al. Randomized Controlled Trial of Resection Versus Radiotherapy After Induction Ch in Stage IIIA-N2 Non-Small-Cell Lung Cancer. J Natl Cancer Inst 2007;99:442-50.

52. Schwartz RM, Alpert N, Rosenzweig K, et al. Changes in quality of life after surgery or radiotherapy in early-stage lung cancer. J Thorac Dis 2019;11:154-61.

53. Pless M, Stupp R, Ris H, et al. Induction chemoradiation in stage IIIA/N2 non-small-cell lung cancer: a phase 3 randomised trial. Lancet 2015;386:1049-56.

54. Thomas M, Rübe C, Hoffknecht P, et al. Effect of preoperative chemoradiation in addition to preoperative Ch: a randomised trial in stage III non-small-cell lung 
cancer. Lancet Oncol 2008;9:636-48.

55. Sorensen JB, Ravn J, Pilegaard HK, et al. Surgery for NSCLC stages T1-3N2M0 having preoperative pathologically verified N2 involvement: a prospective randomized multinational phase III trial by the Nordic Thoracic Oncology Group. J Clin Oncol 2013;31:7504.

56. McElnay PJ, Choong A, Jordan E, et al. Outcome of surgery versus radiotherapy after induction treatment in patients with $\mathrm{N} 2$ disease: systematic review and metaanalysis of randomised trials. Thorax 2015;70:764-8.

57. Schumacher A, Riesenbeck D, Braunheim M, et al. Combined modality treatment for locally advanced nonsmall cell lung cancer: preoperative chemoradiation does not result in a poorer quality of life. Lung Cancer 2004;44:89-97.

58. European Organisation for Research and Treatment of Cancer. EORTC QLQ - LC13. Available online: https:// www.eortc.org/app/uploads/sites/2/2018/08/SpecimenLC13-English.pdf (accessed 25th May 2020).

59. Pritchard RS, Anthony SP. Chemotherapy plus radiotherapy compared with radiotherapy alone in the treatment of locally advanced, unresectable, non-smallcell lung cancer. A meta- analysis. Ann Intern Med 1996;125:723-9.

60. Aupérin A, Le Péchoux C, Rolland E, et al. Meta-analysis of concomitant versus sequential radiochemotherapy in locally advanced non-small-cell lung cancer. J Clin Oncol 2010;28:2181-90.

61. Curran WJ Jr, Paulus R, Langer CJ, et al. Sequential vs. concurrent chemoradiation for stage III non-small cell lung cancer: randomized phase III trial RTOG 9410. J Natl Cancer Inst 2011;103:1452-60.

62. Strøm HH, Bremnes R, Sundstrøm S, et al. Concurrent palliative chemoradiation leads to survival and quality of life benefits in poor prognosis stage III non-small-cell lung cancer: a randomised trial by the Norwegian Lung Cancer Study Group. Br J Cancer 2013;109:1467-75.

63. Pijls-Johannesma M, Houben R, Boersma L, et al. Highdose radiotherapy or concurrent chemo-radiation in lung cancer patients only induces a temporary, reversible decline in QoL. Radiother Oncol 2009;91:443-8.

64. Antonia SJ, Vilegas A, Daniel D, et al. Overall Survival with Durvalumab after Chemoradiotherapy in Stage III NSCLC. New Eng J Med 2018;379:2342-50.

65. Antonia SJ, Vilegas A, Daniel D, et al. Durvalumab after Ch in Stage III Non-Small-Cell Lung Cancer. New Eng J Med 2017;377:1919-29.

66. O'Rourke N, Roqué I Figuls M, et al. Concurrent chemoradiotherapy in non-small cell lung cancer. Cochrane Database Syst Rev 2010;(6):CD002140.

67. Furuse K, Fukuoka M, Kawahara M, et al. Phase III study of concurrent versus sequential thoracic radiotherapy in combination with mitomycin, vindesine, and cisplatin in unresectable stage III non-small-cell lung cancer. J Clin Oncol 1999;17:2692-9.

68. Iyengar P, Gerber DE. Locally advanced lung cancer: an optimal setting for vaccines and other immunotherapies. Cancer J 2013;19:247-62.

69. Chalmers AW, Patel SB, Akerley W. Immunotherapy after chemoradiotherapy in stage III non-small cell lung cancer: a new standard of care? J Thorac Dis 2018;10:1198-200.

70. Hui R, Özgüroğlu M, Villegas A, et al. Patient-reported outcomes with durvalumab after chemoradiotherapy in stage III, unresectable non-small-cell lung cancer (PACIFIC): a randomised, controlled, phase 3 study. Lancet Oncol 2019;20:1670-80.

71. Garassino MC, Paz-Ares L, Hui R, et al. Patient-reported outcomes (PROs) with durvalumab by PD-L1 expression in unresectable, stage III NSCLC (PACIFIC). Ann Oncol 2019;30:ii77-ii80.

72. Brahmer J, Reckamp KL, Baas P, et al. Nivolumab versus Docetaxel in Advanced Squamous-Cell Non-Small-Cell Lung Cancer. N Engl J Med 2015;373:123-35.

73. Carbone DP, Reck M, Paz-Ares L, et al. First-Line Nivolumab in Stage IV or Recurrent Non-Small-Cell Lung Cancer. N Engl J Med 2017;376:2415-26.

74. Borghaei H, Paz-Ares L, Horn L, et al. Nivolumab versus Docetaxel in Advanced Nonsquamous Non-Small-Cell Lung Cancer. N Engl J Med 2015;373:1627-39.

75. Fehrenbacher L, Spira A, Ballinger M, et al. Atezolizumab versus docetaxel for patients with previously treated non-small-cell lung cancer (POPLAR): a multicentre, open-label, phase 2 randomised controlled trial. Lancet 2016;387:1837-46.

76. Rittmeyer A, Barlesi F, Waterkamp D, et al. Atezolizumab versus docetaxel in patients with previously treated non-small-cell lung cancer (OAK): a phase 3, openlabel, multicentre randomised controlled trial. Lancet 2017;389:255-65.

77. Herbst RS, Baas P, Kim DW, et al. Pembrolizumab versus docetaxel for previously treated, PD-L1-positive, advanced non-small-cell lung cancer (KEYNOTE-010): a randomised controlled trial. Lancet 2016;387:1540-50.

78. Langer CJ, Gadgeel SM, Borghaei H, et al. Carboplatin and pemetrexed with or without pembrolizumab for 
advanced, non-squamous non-small-cell lung cancer: a randomised, phase 2 cohort of the open-label KEYNOTE-021 study. Lancet Oncol 2016;17:1497-508.

doi: $10.21037 /$ ccts-20-114

Cite this article as: Trevis J, Barclay P, Marshall N, Pompili C. Narrative review of the management of stage IIIA non-small cell lung cancer: does different management equal different quality of life? Curr Chall Thorac Surg 2022;4:15.
79. Reck M, Rodríguez-Abreu D, Robinson AG, et al. Pembrolizumab versus Ch for PD-L1- Positive Non-SmallCell Lung Cancer. N Engl J Med 2016;375:1823-33. 